\title{
Effect of compatibiliser on the properties of polypropylene/ glass fibre/nanoclay composites
}

\author{
Normasmira Abd Rahman*, Aziz Hassan ${ }^{1}$ and Javad Heidarian \\ ${ }^{1}$ Polymer and Composite Materials Research Laboratory, Department of Chemistry, \\ University of Malaya, Kuala Lumpur, Malaysia \\ *nmmira@um.edu.my; nmmira14@gmail.com
}

\begin{abstract}
Glass fibre (GF), nanoclay (NC) and hybrid composites compatibilised with maleic anhydride polypropylene (MAPP) were prepared by extrusion and injection moulding. The fourier transform infra-red spectra revealed the characteristic absorption peaks of MAPP in the compatibilised GF and NC composites. A decrement in the peak intensity of X-ray diffraction patterns of NC composite was obtained as the MAPP content increased indicating a partial exfoliation of NC. The thermogravimetric analysis showed that the incorporation of MAPP into hybrid composites reduced the thermal stability of the material. The dynamic mechanical analysis showed an increase in the storage modulus in the hybrid composites with lower content of MAPP due to the enhancement in the interfacial adhesion between the GF, $\mathrm{NC}$ and PP matrix.
\end{abstract}

Keywords: compatibiliser, dynamic mechanical properties, hybrid materials, thermal behavior.

\section{Introduction}

Polypropylene (PP), one of the most exploited thermoplastic resins in the composites, alloy and blends industries ${ }^{[1]}$, possesses outstanding properties like low density, good abrasion resistance and excellent electrical properties $^{[2]}$. However, to cope with some limitations of PP, for example, low stiffness and low strength, and to expand their applications in different sectors, inorganic fillers, such as glass fibre (GF), carbon nanotubes and clays, are often added when processing the polymer composites, which normally combine the advantages of their constituent phases ${ }^{[3]}$. Of these composites, glass fibre reinforced PP composite is quite attractive because of their ease of fabrication, superior mechanical properties, high specific modulus and strength and low manufacturing $\operatorname{cost}^{[4]}$.

Meanwhile, a relatively new development in polymer-clay nanocomposites $(\mathrm{PCN})$ has attracted great interest as they exhibit remarkable improvement in the material properties. Researchers first demonstrated that the properties of nylon- 6 , containing a homogenous dispersion of $2-7 \mathrm{wt} \%$ of nanoclay (NC) showed excellent mechanical, thermal and barrier properties when compared with non-reinforced nylon ${ }^{[5,6]}$. A number of other researchers also began an investigations with various types of polymer nanocomposites ${ }^{[7-9]}$.

Recently, it has been observed that by hybridising nanoparticles into the matrix of fibre-reinforced composites, synergistic effects may be achieved ${ }^{[10-12]}$. Mohan and Kanny ${ }^{[13]}$ in their work, combined PP/NC composite with chopped GF. A small amount $(5 \mathrm{wt} \%$ ) of nanoscale dispersed layered silicate was shown to enhance the degree of crystallinity as well as the tensile properties. Using nano reinforcements in a GF reinforced PP matrix, Cui et al. ${ }^{[14]}$ observed that the addition of $2 \mathrm{wt} \%$ nano- $\mathrm{ZnO}$ in $40 \mathrm{wt} \%$ GF composite gave the optimum mechanical properties. However, the extent to which fillers can vary the properties of the resultant composite parts is depends on the nature of adhesion between the filler and the matrix.

Although a number of reports have been published on the use of maleic anhydride grafted polypropylene (MAPP) as compatibiliser for PP composites, there is very little information available regarding the effect of compatibiliser in the hybrid composite systems ${ }^{[15]}$. For this reason, in this paper, the function/role of MAPP as coupling agent in $\mathrm{PP} / \mathrm{GF} / \mathrm{NC}$ hybrid composites prepared through a melt processing method is investigated. Chemical analyses and microstructure characteristics were used to evaluate the composites.

\section{Experimental}

\section{1 Materials}

Chopped E-glass fibre (GF) with the density of $2,550 \mathrm{~kg} \mathrm{~m}^{-3}$, average diameter of $14 \mu \mathrm{m}$, and length of $6 \mathrm{~mm}$ was used as a principal reinforcement. It was obtained from $\mathrm{KCC}$ Corporation, Korea. The nanoclay (NC, type PGV), was a natural, untreated montmorillonite clay, with a particle size of about $16 \mu \mathrm{m}$ and a density of $776 \mathrm{~kg} \mathrm{~m}^{-3}$ and manufactured by Nanocor, USA. Commercially available polypropylene (PP, Propelinas H022), with a density of $910 \mathrm{~kg} \mathrm{~m}^{-3}$ and melt flow index of $11 \mathrm{~g} / 10 \mathrm{~min}$ (at $230{ }^{\circ} \mathrm{C}, 2.16 \mathrm{~kg}$ load), was supplied by Petronas, Malaysia and used as the matrix. Maleic anhydride grafted polypropylene (MAPP, Polybond 3200) with density of $910 \mathrm{~kg} \mathrm{~m}^{-3}$ was supplied by Chemtura Corporation, USA (formerly Crompton Corporation) and used as the compatibiliser. 


\subsection{Specimen preparation}

In order to produce composites materials, PP, nanoclay, glass fibre and MAPP were pre-mixed in different compositions, as presented in Table 1. The materials were then compounded using the Brabender, KETSE 20/40 (Germany) twin-screw extruder with the screw diameter and screw aspect ratio of $20 \mathrm{~mm}$ and 40 , respectively. The temperature profile was set between $185^{\circ} \mathrm{C}$ and $190^{\circ} \mathrm{C}$. For the $\mathrm{PP} / \mathrm{GF}$ composites, the screw speed was set to $100 \mathrm{rpm}$, whereas for the $\mathrm{PP} / \mathrm{NC}$ composites, the screw speed used was $800 \mathrm{rpm}$. In order to produce PP/GF/NC composites, the different ratios of the PP/NC pellets and GF were physically mixed and re-compounded in a twin-screw extruder, using the same temperature profile and screw speed of $100 \mathrm{rpm}$. The materials extruded from both formulations were pelletized into length of about $6 \mathrm{~mm}$. The pellets were injection moulded into a dumb-bell shaped tensile test specimens with geometry defined in the ASTM Standard D-638, type $1^{[16]}$ using a Boy ${ }^{\circledR} 55 \mathrm{M}$ (Germany), a 55 tonne clamping force injection moulding machine. The processing temperature was set between $175^{\circ} \mathrm{C}$ and $185^{\circ} \mathrm{C}$ and the mould temperature was set at $25^{\circ} \mathrm{C}$. The screw speed was maintained at $30-50 \mathrm{rpm}$. The list and abbreviation of specimens prepared are given in Table 1. Specimens were designated according to their composition; for example, (PP80:C5/G15)/NC6 referred to specimen with $80 \mathrm{wt} \%$ of PP, $5 \mathrm{wt} \%$ of MAPP, $15 \mathrm{wt} \%$ of GF and $6 \mathrm{phr}$ of NC.

\subsection{Chemical and microstructural characterisations}

FTIR spectra of samples were recorded using the FTIR spectrophotometer (Spotlight 400, Perkin Elmer, USA) at a resolution of $4 \mathrm{~cm}^{-1}$ for 64 scans in the range of $650-4000 \mathrm{~cm}^{-1}$. Powdered clay and clay nanocomposites were analysed by XRD using Philips-binary diffractometer and scanned over the interval of $2 \Theta=2^{\circ}-30^{\circ}$ at $40 \mathrm{kV}$ and $30 \mathrm{~mA}$, with $\mathrm{CuK}_{\alpha}$ radiation. The fractured surface of the various nanocomposites with a thin layer of gold coated on the surface (thickness of $0.014 \mu \mathrm{m}$ ) was examined using a SEM model Auriga ${ }^{\circledR}$ Zeiss (Germany). The microstructure of the PP/NC6 and PP/GF15/NC6 composites with a nominal thickness of $200 \mathrm{~nm}$ were analysed with a Hitachi H-600 (Japan) TEM. Bright-field TEM images of the composites were obtained at $300 \mathrm{kV}$ under low-dose conditions.

\subsection{Thermal and dynamic mechanical analysis}

Thermogravimetric analysis (TGA) measurements were carried out using the Perkin Elmer TGA(USA) 6 on $5-10 \mathrm{mg}$ samples of each of the composites in a ceramic crucible, over a temperature range from 50 to $850^{\circ} \mathrm{C}$ at a heating rate of $10^{\circ} \mathrm{C} \mathrm{min}^{-1}$. The tests were conducted in a nitrogen atmosphere at a flow rate of $20 \mathrm{~mL} \mathrm{~min}^{-1}$.

Test specimens for dynamic mechanical analysis were taken from the middle section of the injection moulded dumb-bell test bar with dimensions of $60.0 \mathrm{~mm} \times 13.0 \mathrm{~mm}$ $\times 3.3 \mathrm{~mm}$ (length $\times$ width $\times$ thickness) characterised using dynamic mechanical analyser, Thermal Analysis Instrument, TAI Q800 (USA). Measurements were conducted over a temperature range from $-100^{\circ} \mathrm{C}$ to $110^{\circ} \mathrm{C}$ with a heating rate of $3{ }^{\circ} \mathrm{C} \mathrm{min}^{-1}$ at a constant frequency and amplitude of $1.0 \mathrm{~Hz}$ and $15 \mu \mathrm{m}$, respectively. Specimens were subjected to a three-point bending mode with a support span of $50 \mathrm{~mm}$.

\section{Results and discussion}

\subsection{Fourier-transform infra-red (FTIR)}

The FTIR spectra of PP matrix, MAPP, NC and composites in the region of $650 \mathrm{~cm}^{-1}$ to $4000 \mathrm{~cm}^{-1}$ are given in Figure 1. The bands at $1375 \mathrm{~cm}^{-1}$ and $1451 \mathrm{~cm}^{-1}$ are the characteristic of polypropylene. In the case of MAPP, absorption bands at $1700 \mathrm{~cm}^{-1}$ and $1750 \mathrm{~cm}^{-1}$ are observed, which are assigned to the absorption of carbonyl groups $(\mathrm{C}=\mathrm{O})$ of maleic anhydride (MA) $)^{[17]}$. Therefore, it is confirmed that MA was grafted onto the PP backbone. Meanwhile, for NC, the band at $3588 \mathrm{~cm}^{-1}$ is attributed to the hydroxyl stretching of Al-OH and $\mathrm{Si}-\mathrm{OH}^{[18]}$. The broad band in the region of $700 \mathrm{~cm}^{-1}$ to $1100 \mathrm{~cm}^{-1}$ is mainly due to the contribution of several structural $-\mathrm{OH}$ groups in the clay ${ }^{[19]}$. Moreover, the absorption in the regions of $1624 \mathrm{~cm}^{-1}$ is assigned to $-\mathrm{OH}$

Table 1. Designation and compositions of composite specimens.

\begin{tabular}{lcccc}
\hline \multicolumn{1}{c}{ Sample } & $\begin{array}{c}\text { Matrix weight fraction, } \\
\boldsymbol{W}_{\boldsymbol{M}}(\mathbf{\%})\end{array}$ & $\begin{array}{c}\text { MAPP weight fraction, } \\
\boldsymbol{W}_{\text {MAPP }}(\mathbf{\%})\end{array}$ & $\begin{array}{c}\text { Fibre weight fraction, } \\
\boldsymbol{W}_{\boldsymbol{F}}(\mathbf{\%})\end{array}$ & $\begin{array}{c}\text { Clay content } \\
(\mathbf{p h r})\end{array}$ \\
\hline NC powder & - & - & - & - \\
PP & 100 & 0 & 0 & 0 \\
(PP100:C0)/NC6 & 100 & 0 & - & 6 \\
(PP98:C2)/NC6 & 98 & 2 & - & 6 \\
(PP95:C5)/NC6 & 95 & 5 & - & 6 \\
(PP92:C8)/NC6 & 92 & 8 & - & 6 \\
(PP85:C0/G15) & 85 & 0 & 15 & - \\
(PP83:C2/G15) & 83 & 2 & 15 & - \\
(PP80:C5/G15) & 80 & 5 & 15 & - \\
(PP77:C8/G15) & 77 & 8 & 15 & 6 \\
(PP85:C0/G15)/NC6 & 85 & 0 & 15 & 6 \\
(PP83:C2/G15)/NC6 & 83 & 2 & 15 & 6 \\
(PP80:C5/G15)/NC6 & 80 & 5 & 15 & 6 \\
(PP77:C8/G15)/NC6 & 77 & 8 & 15 & 6 \\
\hline
\end{tabular}


bending mode in adsorbed water. Meanwhile, the band at 1092 $\mathrm{cm}^{-1}$ is attributed to $\mathrm{Si}-\mathrm{O}$ stretching (in-plane) vibration for layered NC. The bands at $902 \mathrm{~cm}^{-1}, 864 \mathrm{~cm}^{-1}$ and $826 \mathrm{~cm}^{-1}$ are attributed to $\mathrm{Al}_{2} \mathrm{OH}, \mathrm{AlFeOH}$ and $\mathrm{AlMgOH}$ bending vibrations, respectively ${ }^{[19]}$. The characteristic absorption bands of carbonyl groups of MA can be seen at $1722 \mathrm{~cm}^{-1}$ for compatibilised PP/GF15 composite and at $1762 \mathrm{~cm}^{-1}$ and $1693 \mathrm{~cm}^{-1}$ for compatibilised PP/NC6 composite. Again, as mentioned before, a broad band in the region of $700 \mathrm{~cm}^{-1}$ to $1100 \mathrm{~cm}^{-1}$ observed for PP/NC6 composites are related to the characteristic absorption of $\mathrm{NC}$.

\subsection{X-ray diffraction properties}

Several researchers ${ }^{[20,21]}$ have shown that X-ray diffraction method can be used to observe the distribution and dispersion of NC particles in a polymer and to characterise the degree of dispersion. In order to measure the interlayer distance using the diffraction peak and its position in an XRD pattern, the Bragg's equation is typically employed ${ }^{[7]}$. Details of this equation have been explained by Rahman et al. ${ }^{[1]}$. Results from the XRD analyses of composite specimens are shown in Figure 2 and the data extracted from these patterns are tabulated in Table 2.

Figure 2 shows the series of XRD spectra of PP/NC6 composites, in which the concentration of MAPP varied from 0 to $8 \mathrm{wt} \%$. The NC concentration in the composite is constant ( $6 \mathrm{phr}$ ) and the interlayer d-spacing of clay powder is

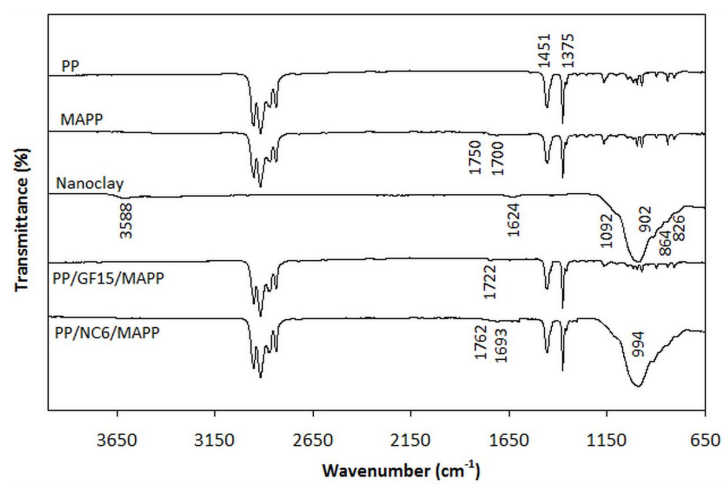

Figure 1. FTIR spectra of PP matrix, MAPP, nanoclay and composites.

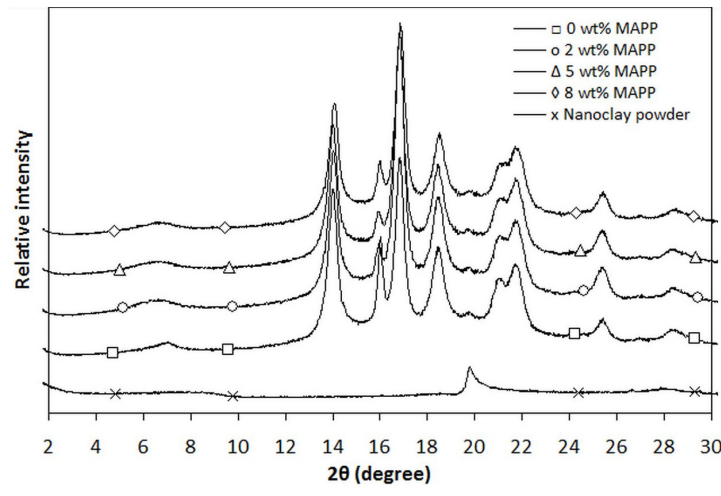

Figure 2. The XRD patterns of nanoclay and PP/6 phr nanoclay composites compatibilised with different MAPP loadings. calculated to be $1.00 \mathrm{~nm}$ (Table 2). For the uncompatibilised system, the XRD patterns exhibited a significant increase in interlayer d-spacing (1.25 $\mathrm{nm}$ after compounding). This indicates that with higher processing screw speed, the $\mathrm{PP}$ is able to intercalate into the NC interlayer, even with poor compatibility between PP and $\mathrm{NC}^{[12]}$.

Furthermore, for compatibilised systems, XRD peaks are continually shifted to lower angles, indicating an increase in interlayer d-spacing by the diffusion of PP chains. The interlayer d-spacing increased from $1.29 \mathrm{~nm}$ for $2 \mathrm{wt} \%$ MAPP to $1.34 \mathrm{~nm}$ for $5 \mathrm{wt} \%$ MAPP. Further addition of $8 w t \%$ of MAPP resulted in insignificant changes in this value. Nevertheless, it should be noted that even though a similar interlayer d-spacing value is obtained at higher MAPP content $(8 \mathrm{wt} \%)$, there is a decrement in the peak intensity. The peak intensity for PP/NC6 composite with $5 \mathrm{wt} \%$ MAPP recorded at 370 counts $\mathrm{s}^{-1}$, reduced to 357 counts $\mathrm{s}^{-1}$ for $8 \mathrm{wt} \%$ MAPP. Lertwimolnun and Vergnes ${ }^{[21]}$ suggested that the decrease in intensity and the broadening of peaks indicate that the stacks of layered silicates become more disordered, while maintaining a periodic distance. In addition, the decrease in intensity could be the result of a partial exfoliation of layered silicates. A higher nucleation effect with the present of MAPP in the system is suggested to be due to the higher interaction between filler and matrix. The phenomenon can be seen in the morphological analysis (Figure 3). The addition of MAPP provided better dispersion of the NC within the matrix thus reducing the particle thickness hence increasing the aspect ratio.

\subsection{Thermogravimetric analysis (TGA)}

The thermal stability of composites was studied by the thermogravimetric analysis (TGA). Figures 4 and 5 show the TGA scans in the form of weight change and derivative weight change (DTG) versus temperature for PP/NC6 and $\mathrm{PP} / \mathrm{GF} 15$ composites. Table 3 presents the quantitative values of the onset temperature, derivative peak temperature, and the temperatures at $5 \%, 10 \%$ and $50 \%$ of weight loss, which are referred to as: $T_{\text {ONSET }}, D T_{P}, T_{5 \%}, T_{10 \%}$ and $T_{50 \%}$, respectively.

Figure 4 illustrates the TGA and DTG curves of the PP/NC6 composites with and without compatibiliser. With the addition of 2-8 $\mathrm{wt} \%$ MAPP in the PP/NC6 composites system, an increase of about $14.5^{\circ} \mathrm{C}$ to $15.1^{\circ} \mathrm{C}$ in the $T_{\text {ONSET }}$ was observed when compared with the uncompatibilised PP/NC6 composites. This improvement is probably due to the physico-chemical adsorption of the volatile products on the clay ${ }^{[22,23]}$ which indicate that the dispersion of clay is improved by the addition of the compatibiliser in the PP/NC6 composites.

Table 2. X-ray diffraction data of nanoclay and clay nanocomposites.

\begin{tabular}{lccc}
\hline \multicolumn{1}{c}{ Sample } & $\boldsymbol{2 \theta}\left(^{\circ}\right)$ & $\begin{array}{c}\text { Interlayer } \\
\text { d-spacing }(\mathbf{n m})\end{array}$ & $\begin{array}{c}\text { Peak intensity } \\
(\text { counts s }\end{array}$ \\
\hline NC powder & 8.86 & 1.00 & 127 \\
(PP100:C0)/NC6 & 7.04 & 1.25 & 320 \\
(PP98:C2)/NC6 & 6.85 & 1.29 & 467 \\
(PP95:C5)/NC6 & 6.60 & 1.34 & 370 \\
(PP92:C8)/NC6 & 6.61 & 1.34 & 357 \\
\hline
\end{tabular}


(a)

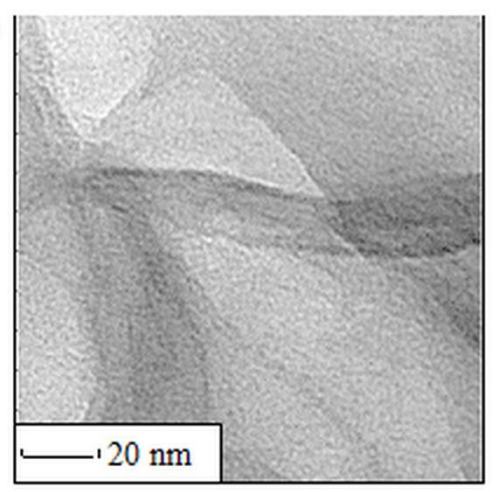

(c)

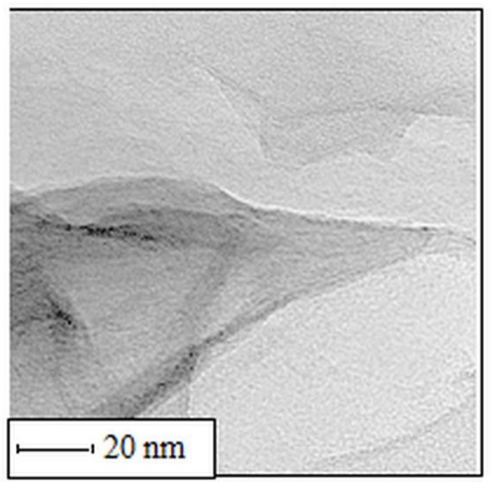

(b)

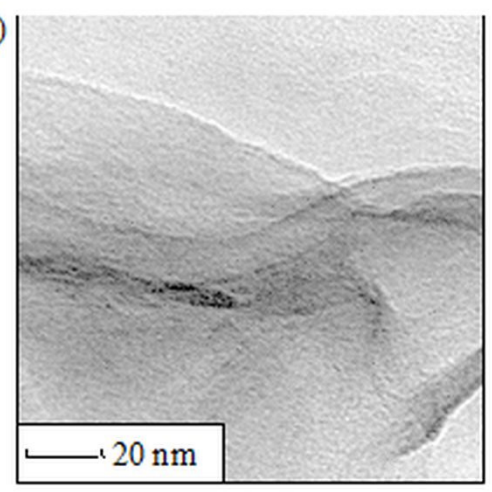

(d)

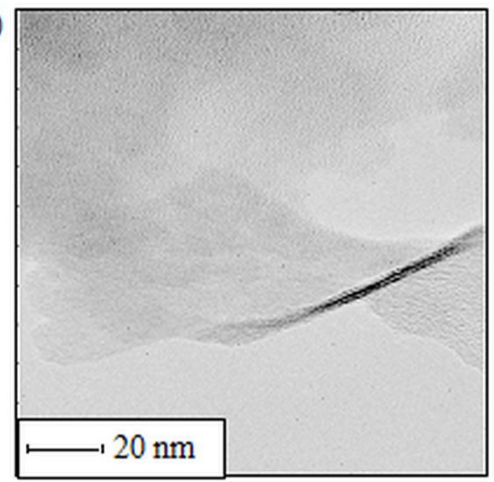

Figure 3. TEM images of PP/ 6 phr nanoclay with (a) 0; (b) 2; (c) 5 and (d) 8 wt $\%$ of MAPP contents.

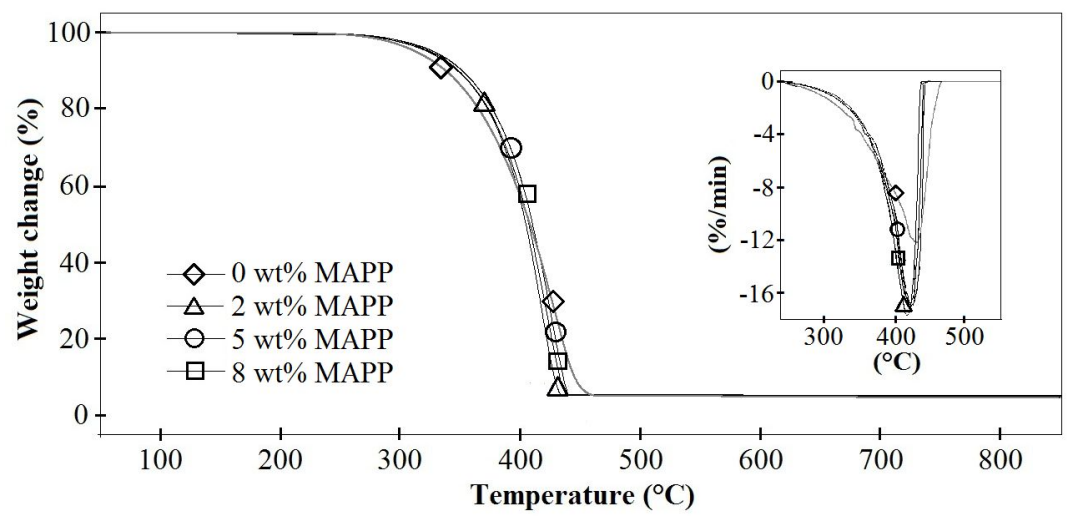

Figure 4. TGA and DTG thermograms of PP/ 6 phr of nanoclay composites with 0 to $8 \mathrm{wt} \%$ of MAPP.

Table 3. TGA data of composites.

\begin{tabular}{ccccccc}
\hline Sample & Range of decomposition $\left({ }^{\circ} \mathbf{C}\right)$ & $T_{\text {ONSET }}\left({ }^{\circ} \mathbf{C}\right)$ & $T_{5 \%}\left({ }^{\circ} \mathbf{C}\right)$ & $T_{10 \%}\left({ }^{\circ} \mathbf{C}\right)$ & $T_{50 \%}\left({ }^{\circ} \mathbf{C}\right)$ & $D T_{P}\left({ }^{\circ} \mathbf{C}\right)$ \\
\hline PP & $228.3-465.7$ & 356.9 & 306.7 & 327.0 & 397.6 & 430.5 \\
$(\mathrm{PP} 100: C 0) / \mathrm{NC} 6$ & $215.2-468.6$ & 360.4 & 309.4 & 334.8 & 406.8 & 429.0 \\
$(\mathrm{PP} 98: \mathrm{C} 2) / \mathrm{NC6}$ & $240.0-441.4$ & 374.9 & 324.3 & 347.2 & 402.9 & 416.0 \\
$(\mathrm{PP} 95: \mathrm{C} 5) / \mathrm{NC6}$ & $239.6-445.0$ & 374.4 & 327.2 & 351.3 & 408.6 & 422.6 \\
$(\mathrm{PP} 92: \mathrm{C} 8) / \mathrm{NC} 6$ & $241.3-444.3$ & 375.5 & 322.5 & 345.5 & 405.9 & 419.5 \\
$(\mathrm{PP} 85: \mathrm{C} 0 / \mathrm{G} 15)$ & $250.1-525.4$ & 423.3 & 368.0 & 396.4 & 471.7 & 480.7 \\
$(\mathrm{PP} 83: \mathrm{C} 2 / \mathrm{G} 15)$ & $249.1-472.9$ & 385.0 & 345.8 & 368.8 & 422.9 & 428.6 \\
$(\mathrm{PP} 80: \mathrm{C} 5 / \mathrm{G} 15)$ & $202.3-450.7$ & 373.4 & 331.9 & 351.5 & 408.1 & 420.4 \\
$(\mathrm{PP} 77: \mathrm{C} 8 / \mathrm{G} 15)$ & $237.9-447.2$ & 357.5 & 320.1 & 341.8 & 339.2 & 409.2 \\
\hline
\end{tabular}


It can also be seen that the initial thermal decomposition temperatures are enhanced by the addition of MAPP into the PP/NC6 composites. The $T_{5 \%}$ increased from $309.4{ }^{\circ} \mathrm{C}$ for uncompatibilised PP/NC6 composite to $324.3{ }^{\circ} \mathrm{C}, 327.2{ }^{\circ} \mathrm{C}$ and $322.5^{\circ} \mathrm{C}$ for PP/NC6 composites containing 2,5 and $8 \mathrm{wt} \%$ of MAPP, respectively. The same trend was observed at $10 \%$ weight change (Table 3 ). It is possible that at this initial degradation event, incorporation of MAPP improved the compatibility and homogeneity between the matrix and the $\mathrm{NC}$, resulting in more thermally stable nanocomposites. By contrast, the $T_{50 \%}$ and $D T_{P}$ values decreased slightly with the incorporation of MAPP into the PP/NC6 system.

Figure 5 shows the TGA and DTG thermograms of $\mathrm{PP} / \mathrm{GF} 15$ composite as a function of MAPP contents. It is observed that the thermal stability of the composites generally reduced with increasing MAPP contents. Better compatibility between PP and GF, expected by the incorporation of MAPP into the composites, may not be the criteria for improvement in the thermal stability.

\subsection{Dynamic mechanical analysis (DMA)}

The dynamic storage modulus $\left(E^{\prime}\right)$ is analogous to the flexural modulus measured as per ASTM D-790 standard $^{[2,24,25]}$ and closely related to the load bearing capacity of a material. The storage modulus values at $-100^{\circ} \mathrm{C}$ and $25^{\circ} \mathrm{C}$ are referred to as $E_{-100^{\circ} \mathrm{C}}^{\prime}$ and $E_{25^{\circ} \mathrm{C}}^{\prime}$, respectively. Variations of $\mathrm{E}^{\prime}$ as a function of temperature for composites are graphically illustrated in Figure 6a-c. A sharp rate of decrease from $-25^{\circ} \mathrm{C}$ to about $25^{\circ} \mathrm{C}$ in $E^{\prime}$ is suggested to be associated

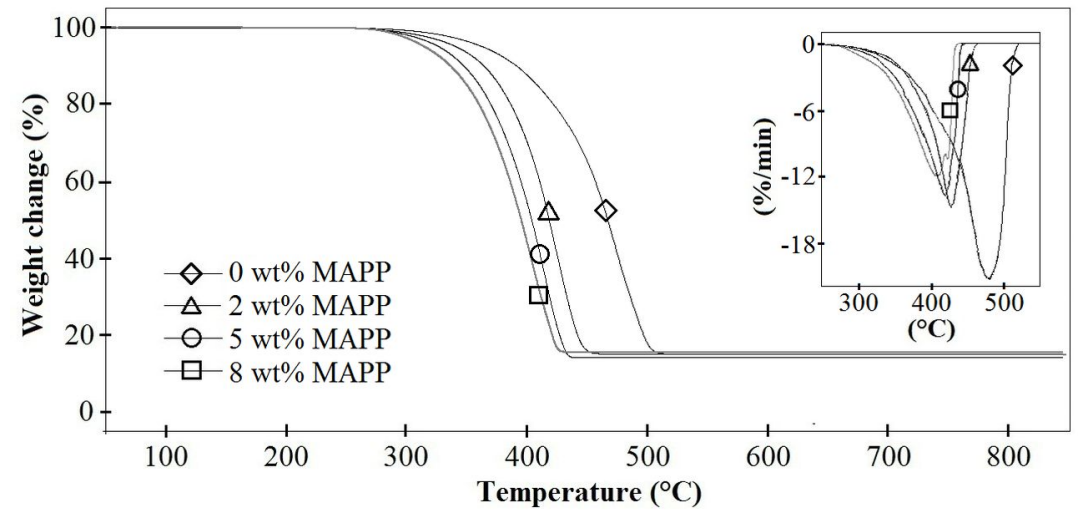

Figure 5. TGA and DTG thermograms of PP/15 wt $\%$ glass fibre composites with 0 to $8 \mathrm{wt} \%$ of MAPP.
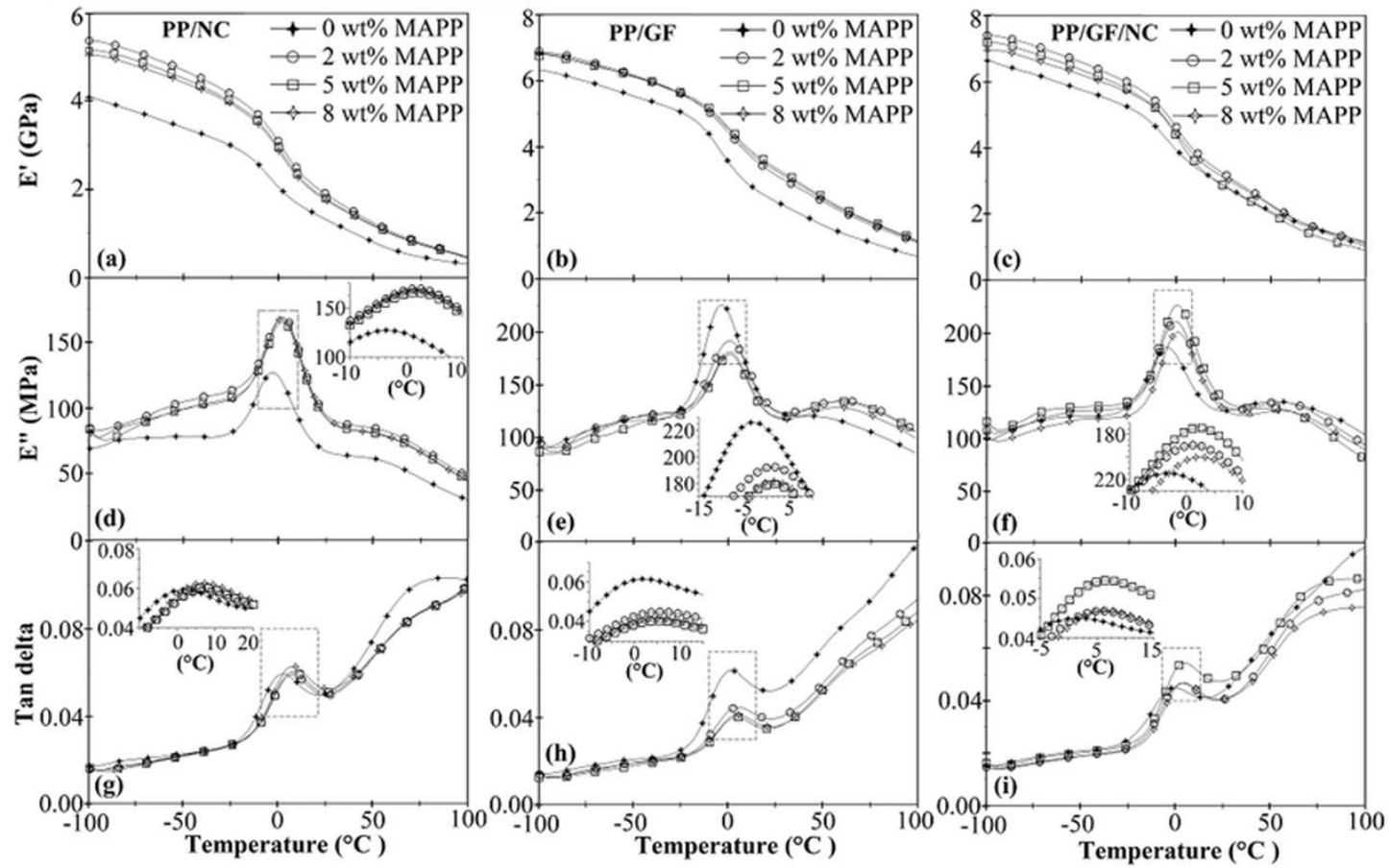

Figure 6. The DMA curves of PP/NC6, PP/GF15 and PP/GF15/NC6 composites with different MAPP contents. 
with the relaxation of the amorphous phase. The glassy state of the amorphous phase in the PP goes through its glass transition, followed by a sharp drop in the modulus.

Figure 6a shows the $E$ ' curves obtained for PP/NC6 composites with variation in MAPP loadings, from 2 to $8 \mathrm{wt} \%$. Apparently, the compatibilised PP/NC6 composites displayed an improved $E$ ' values throughout the experimental temperature range, indicating that more reinforcing effect is being induced by the compatibiliser ${ }^{[26]}$. This scenario is considered to be due to the real reinforcement effect of clays ${ }^{[27]}$. It was also suggested by Modesti et al. ${ }^{[28]}$ and Lai et al. ${ }^{[29]}$ that obvious increment in storage modulus values probably resulted from the better dispersion of the clay in the presence of the compatibiliser. The addition of $2 \mathrm{wt} \%$ of MAPP increased the $E_{-100^{\circ} \mathrm{C}}^{\prime}$ of PP/NC6 composite by about $31 \%$ from $4.10 \mathrm{GPa}$ to $5.38 \mathrm{GPa}$. However, further additions of $5 \mathrm{wt} \%$ and $8 \mathrm{wt} \%$ of MAPP resulted in a lower magnitude of increment to $5.14 \mathrm{GPa}$ and $5.06 \mathrm{GPa}$, respectively. The $E_{25^{\circ} \mathrm{C}}^{\prime}$ values show a similar trend as observed for $E_{-100^{\circ} \mathrm{C}}^{\prime}$. However, the enhancements of the storage modulus values at this higher temperature are less marked compared with at lower temperature.

The incorporation of $15 \mathrm{wt} \%$ of GF into PP matrix greatly increased the value of $E_{-100^{\circ} \mathrm{C}}^{\prime}$ from $4.06 \mathrm{GPa}$ to $6.36 \mathrm{GPa}$ (Table 4). The additions of 2, 5 and $8 \mathrm{wt} \%$ of MAPP into the composite further increased the $E^{\prime}$ value to $6.90,6.88$ and $6.86 \mathrm{GPa}$, respectively (Figure 6b). An improvement in $E$ ' could be due to the enhancement in the interfacial adhesion between the GF and the PP by the presence of compatibiliser in the composite system ${ }^{[2]}$. Through microscopic studies, it can clearly be seen that in the compatibilised composite, some of the polymer matrix adhered to the GF surface indicating a good fibre-matrix adhesion (Figure 7a). Meanwhile, a clean GF surface is observed for uncompatibilised system (Figure 7b) probably due to the weak fibre-matrix interfacial bonding. Figure $6 \mathrm{c}$ shows the storage modulus $\left(E^{\prime}\right)$ curves obtained for $\mathrm{PP} / \mathrm{GF} 15 / \mathrm{NC6}$ hybrid composites with variation in MAPP loadings, from 2 to $8 \mathrm{wt} \%$. Generally, the compatibilised composites displayed improved $E$ ' values throughout the experimental temperature range, following the same trend as previously observed for PP/NC6 and PP/GF15 composites. The addition of $2 \mathrm{wt} \%$ of MAPP into the hybrid composite increased the $E_{-100^{\circ} \mathrm{C}}^{\prime}$ by about $12 \%$ from $6.65 \mathrm{GPa}$ to $7.42 \mathrm{GPa}$. However, further additions of 5 and $8 \mathrm{wt} \%$ of MAPP resulted in a lower magnitude of increment to $7.21 \mathrm{GPa}$ and $6.98 \mathrm{GPa}$, respectively. The $E_{25^{\circ} \mathrm{C}}^{\prime}$ values show a similar trend, as observed for $E_{-100^{\circ} \mathrm{C}}^{\prime}$.

The loss modulus $\left(E^{\prime \prime}\right)$ is most sensitive to the molecular motions ${ }^{[30]}$. In this study, $T_{\alpha}{ }^{E "}$ is referred to as the temperature at the maximum value of loss modulus in the $\alpha$-transition region, while the $E_{\max }^{\prime \prime}$ and $E_{25^{\circ} \mathrm{C}}^{\prime \prime}$ are the

Table 4. DMA thermomechanical data of $\mathrm{PP} / \mathrm{NC}, \mathrm{PP} / \mathrm{GF}$ and $\mathrm{PP} / \mathrm{GF} / \mathrm{NC}$ hybrid composites.

\begin{tabular}{|c|c|c|c|c|c|c|c|c|c|}
\hline \multirow[b]{2}{*}{ Sample } & \multicolumn{3}{|c|}{ Storage modulus $\left(E^{\prime}\right)$} & \multicolumn{3}{|c|}{ Loss modulus ( $E ")$} & \multicolumn{3}{|c|}{ Tan delta } \\
\hline & $\begin{array}{c}T_{\alpha} \\
\left({ }^{\circ} \mathrm{C}\right)\end{array}$ & $\begin{array}{l}E_{-100^{\circ} \mathrm{C}}^{\prime} \\
\text { (GPa) }\end{array}$ & $\begin{array}{c}E_{25^{\circ} \mathrm{C}}^{,} \\
(\mathbf{G P a})\end{array}$ & $\begin{array}{l}T_{\alpha}^{E^{\prime}} \\
\left({ }^{\circ} \mathrm{C}\right)\end{array}$ & $\begin{array}{c}E_{\max }^{\prime \prime} \\
\text { (MPa) }\end{array}$ & $\begin{array}{c}E_{25^{\circ} \mathrm{C}}^{\prime \prime} \\
\text { (MPa) }\end{array}$ & $\begin{array}{c}T_{G} \\
\left({ }^{\circ} \mathrm{C}\right)\end{array}$ & $\begin{array}{c}\tan \delta_{M A X} \\
\left(\times 10^{-2}\right)\end{array}$ & $\begin{array}{c}\tan \delta_{25^{\circ} \mathrm{C}} \\
\left(\times 10^{-2}\right)\end{array}$ \\
\hline $\mathrm{PP}$ & -16.3 & 4.06 & 1.28 & -2.3 & 140.2 & 74.9 & 2.9 & 6.7 & 5.9 \\
\hline (PP100:C0)/NC6 & -16.1 & 4.10 & 1.33 & -3.5 & 126.9 & 66.9 & 1.7 & 5.9 & 5.0 \\
\hline (PP98:C2)/NC6 & -12.2 & 5.38 & 1.91 & 1.7 & 169.0 & 94.4 & 6.6 & 5.9 & 5.0 \\
\hline (PP95:C5)/NC6 & -11.0 & 5.15 & 1.80 & 1.7 & 165.2 & 91.7 & 6.5 & 6.0 & 5.1 \\
\hline (PP92:C8)/NC6 & -11.2 & 5.06 & 1.77 & 1.7 & 167.9 & 92.7 & 6.7 & 6.3 & 5.2 \\
\hline (PP85:C0/G15)/NC6 & -17.1 & 6.65 & 2.94 & -3.3 & 185.2 & 125.3 & 1.1 & 4.5 & 4.3 \\
\hline (PP83:C2/G15)/NC6 & -10.9 & 7.42 & 3.29 & 1.1 & 210.0 & 132.0 & 5.6 & 4.7 & 4.0 \\
\hline (PP80:C5/G15)/NC6 & -10.9 & 7.21 & 2.91 & 2.0 & 225.5 & 138.3 & 6.6 & 5.5 & 4.7 \\
\hline (PP77:C8/G15)/NC6 & -10.6 & 6.98 & 3.17 & 2.3 & 199.7 & 129.0 & 6.3 & 4.7 & 4.0 \\
\hline
\end{tabular}
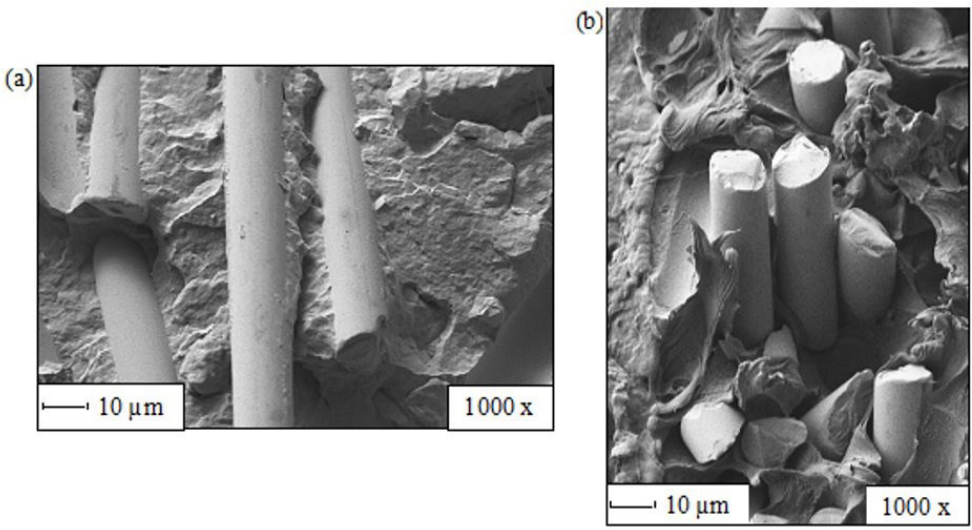

Figure 7. SEM images of tensile fracture surfaces of PP $/ 15 \mathrm{wt} \%$ glass fibre composites with (a) 5 and (b) $0 \mathrm{wt} \%$ of MAPP contents. 
magnitude of loss modulus at $T_{\alpha}{ }^{E \prime}$ and at $25^{\circ} \mathrm{C}$, respectively. The variation of $E^{\prime \prime}$ as a function of temperature for PP/NC6, PP/GF15 and PP/GF15/NC6 composites are graphically illustrated in Figure 6d-f. Figure 6d shows the $E^{\prime \prime}$ curves obtained for PP/NC6 composites with 0 to $8 \mathrm{wt} \%$ MAPP loadings. It is evident from this figure that there is a significant increase in the $T_{\alpha}{ }^{E "}$ values from $-3.5^{\circ} \mathrm{C}$ for PP/NC6 to $1.7{ }^{\circ} \mathrm{C}$ with the addition of $2 \mathrm{wt} \%$ MAPP. No significant changes are observed with further additions of 5 and $8 \mathrm{wt} \%$ MAPP. The increment in $T_{\alpha}{ }^{E "}$ may be attributed to the presence of MAPP which improved the interfacial adhesion between PP and $\mathrm{NC}$, thus resulting in a reduction in the mobility of the polymer chains in the amorphous phase of the PP matrix.

Figure 6e shows the effect of MAPP content on the $E^{\prime \prime}$ of PP/GF15 composites. The $T_{\alpha}{ }^{E "}$ values of the compatibilised composites shifted to higher temperature as compared to the uncompatibilised composite and PP matrix, which is probably due to restricted of the segmental motion in the amorphous PP chains at the fibre-matrix interface ${ }^{[31]}$. This suggests that the more restricted motion of the polymer molecules due to the increased fibre-matrix adhesion in the presence of MAPP resulted in less distinct and broader transition peaks ${ }^{[2]}$. The $E_{\max }^{\prime \prime}$ value decreased generally with MAPP loading. Meanwhile, the values of $E_{25^{\circ} \mathrm{C}}^{\prime \prime}$ for compatibilised composites showed only a slight decrement as the MAPP content increased when compared with uncompatibilised ones. The same trend was observed by Nayak and Mohanty ${ }^{[31]}$. It can be suggested that transition at higher temperature do not change irrespective of the interface modification and hybridisation. Figure $6 \mathrm{f}$ shows the $E^{\prime \prime}$ curves obtained for PP/G15/NCUT6 hybrid composites with variation in MAPP loading, from 2 to $8 \mathrm{wt} \%$. Generally, the compatibilised hybrid composites displayed improved $E^{\prime \prime}$ values throughout the experimental temperature range. The addition of $2 \mathrm{wt} \%$ of MAPP into PP/GF15/NC6 hybrid composite shifted the $T_{\alpha}{ }^{E "}$ of hybrid composites from $-3.3^{\circ} \mathrm{C}$ to $1.1^{\circ} \mathrm{C}$. No significant changes are observed with further additions of 5 and $8 \mathrm{wt} \%$ MAPP. The increment in $T_{\alpha}{ }^{E "}$ may be attributed to the presence of MAPP which improved the interfacial adhesion between PP and nanoclay. This observation is also similar with the trend observed for PP/NC6 and PP/GF15 composites. The maximum $E_{\max }^{\prime \prime}$ value is obtained with the addition of $5 \mathrm{wt} \%$ MAPP.

The ratio of the loss modulus to the storage modulus is measured as the damping factor or mechanical loss $(\tan \delta)^{[2,12]}$. Since the damping peak occurred in the region of the glass transition where the material changed from a rigid to a more elastic state, it is associated with the movement of small groups and chains of molecules within the polymer structure ${ }^{[30]}$. In a composite system, damping is affected by the incorporation of fibres. This is due mainly to stress concentration at the fibre ends in association with the additional viscoelastic energy dissipation in the matrix material. Chen et al. ${ }^{[32]}$ reported that the $\tan \delta$ curve of pure PP is generally related to three relaxations localised in the neighbourhood of $-50^{\circ} \mathrm{C}$, $10^{\circ} \mathrm{C}$ and $100{ }^{\circ} \mathrm{C}$. The variations of $\tan \delta$ as a function of temperature are represented in Figure $6 \mathrm{~g}$-i. In this work, $T_{G}$ is referred to as the temperature at the maximum value of $\tan \delta$, while the $\tan \delta_{M A X}$ and $\tan \delta_{25^{\circ} \mathrm{C}}$ are the magnitude of $\tan \delta$ at $T_{G}$ and at $25^{\circ} \mathrm{C}$, respectively.

Figure $6 \mathrm{~g}$ shows the effects of the compatibiliser loadings on the $\tan \delta$ curves for PP/NC6 composites.
A remarkable shift in $T_{G}$ to a higher temperature is recorded with the presence of MAPP. The $T_{G}$ is shifted from $1.7^{\circ} \mathrm{C}$ for uncompatibilised PP/NC6 composite to $6.6^{\circ} \mathrm{C}$ with the addition of $2 \mathrm{wt} \%$ MAPP into the system. Further additions of 5 and $8 \mathrm{wt} \%$ of MAPP did not change the $T_{G}$ significantly, but only stabilised the temperature. The addition of $6 \mathrm{phr}$ NC in PP matrix resulted in a decrement in the $\tan \delta_{\max }$ value relative to $\mathrm{PP}$, which indicates that the materials experienced a strengthening effect ${ }^{[2,12]}$. No changes in $\tan \delta_{\text {MAX }}$ has been observed with the presence of low MAPP loading $(2 \mathrm{wt} \%)$. However, the additions of 5 and $8 \mathrm{wt} \%$ MAPP increased this value. Although the presence of compatibiliser is expected to increase the interfacial bonding between PP and NC, hence reduced the $\tan \delta_{\max }$, it is suggested by Lee et al. ${ }^{[26]}$ that higher content of MAPP will act as a lubricating modifier at the glass transition temperature region and results in an increment in this value.

The presence of GF in the system has lowered the value of $\tan \delta_{M A X}$ relative to PP matrix. Even though the GF content is suggested to be the major factor in determining the tan $\delta_{\text {MAX }}$, the interaction between GF and PP is also expected to affect the damping properties of composites. The incorporation of 2 to $8 \mathrm{wt} \%$ compatibiliser in PP/GF15 composites resulted in a further reduction in this value (Figure 6h). The tan $\delta_{M A X}$ for PP/GF15 is recorded at 0.061 and this value dropped to 0.041 as $8 \mathrm{wt} \%$ of MAPP is added. An improvement in the interfacial bonding in the composites is shown by a decrement in $\tan \delta_{M A X}$ value with the addition of MAPP ${ }^{[2]}$. Nayak and Mohanty ${ }^{[31]}$ have also suggested that a better adhesion between the filler and matrix will result in a lower damping property. Figure 6 i shows the $\tan \delta$ curves obtained for PP/GF15/NC6 composites with variation in MAPP loadings, from 2-8 wt $\%$. A remarkable shift of $T_{C}$ to a higher temperature is recorded with the presence of MAPP. The $T_{G}$ is shifted from $1.1^{\circ} \mathrm{C}$ in the uncompatibilised hybrid composite to $5.6{ }^{\circ} \mathrm{C}$ with the addition of $2 \mathrm{wt} \%$ MAPP into the system. Further additions of 5 and $8 \mathrm{wt} \%$ of MAPP only stabilised the $T_{G}$ value. This appreciable change implied that an improvement in the interfacial adhesion between the GF, $\mathrm{NC}$ and PP matrix itself has been achieved. However, the presence of the MAPP slightly increased the magnitude of tan $\delta_{\text {MAX }}$ values. This phenomenon could be related to the lubricating effect of the compatibiliser at higher MAPP content. The PP/GF15/NC6 hybrid composites with the addition of $5 \mathrm{wt} \%$ MAPP shows the highest value of tan $\delta_{\text {MAX }}(0.055)$ when compared with other MAPP loadings. The $\tan \delta_{25^{\circ} \mathrm{C}}$ values also show a similar trend.

\section{Conclusions}

The FTIR spectroscopic investigations confirmed that the maleic anhydride was present in the compatibilised composites. TGA demonstrated that the thermal stability of nanocomposites was enhanced by the addition of MAPP in the system. Dynamic mechanical analysis showed that the compatibilised composites possessed higher storage modulus than the uncompatibilised systems. In addition, a remarkable shift of $T_{G}$ to a higher temperature was recorded with the presence of MAPP. However, the incorporation of higher content of MAPP in the PP/NC6 and PP/GF15/NC6 composites increased the $\tan \delta_{\text {MAX }}$ values due to lubricating effect by the compatibiliser. On the other hand, the addition of MAPP into PP/GF15/NC6 hybrid composites enhanced 
better interfacial adhesion between the components, leading to enhanced thermal and dynamic mechanical properties of the resultant composites.

\section{Acknowledgements}

The authors wish to thank the University of Malaya who supported the work reported in this paper with grants UMRG (RG343-15AFR) and BKP (BK009-2014).

\section{References}

1. Gill, R. M. (1972). Carbon fibres in composite materials. London: Iliffe Books for the Plastics Institute.

2. Hassan, A., Rahman, N. A., \& Yahya, R. (2011). Extrusion and injection-molding of glass fiber/MAPP/polypropylene: effect of coupling agent on DSC, DMA and mechanical properties. Journal of Reinforced Plastics and Composites, 30(14), 12231232. http://dx.doi.org/10.1177/0731684411417916.

3. Fu, S. Y., Feng, X. Q., Lauke, B., \& Mai, Y. W. (2008). Effects of particle size, particle/matrix interface adhesion and particle loading on mechanical properties of particulate-polymer composites. Composites. Part B, Engineering, 39(6), 933-961. http://dx.doi.org/10.1016/j.compositesb.2008.01.002.

4. Schwartz, M. (1992). Composite materials handbook. 2nd ed. New York: McGraw-Hill.

5. Kojima, Y., Usuki, A., Kawasumi, M., Okada, A., Kurauchi, T. T., \& Kamigaito, O. (1993). Synthesis of nylon 6-clay hybrid by montmorillonite intercalated with $\epsilon$-caprolactam. Journal of Polymer Science. Part A, Polymer Chemistry, 31(4), 983-986. http://dx.doi.org/10.1002/pola.1993.080310418.

6. Kojima, Y., Usuki, A., Kawasumi, M., Okada, A., Fukushima, Y., Kurauchi, T. T., \& Kamigaito, O. (1993). Mechanical properties of nylon 6-clay hybrid. Journal of Materials Research, 8(5), 1185-1189. http://dx.doi.org/10.1557/JMR.1993.1185.

7. Haque, A., Shamsuzzoha, M., Hussain, F., \& Dean, D. (2003). S2-glass/epoxy polymer nanocomposites: Manufacturing, structures, thermal and mechanical properties. Journal of Composite Materials, 37(20), 1821-1837. http://dx.doi. org/10.1177/002199803035186.

8. Giannelis, E. P. (1996). Polymer layered silicate nanocomposites. Journal of Advanced Materials, 8(1), 29-35. http://dx.doi. org/10.1002/adma.19960080104.

9. Okada, A., Fukushima, Y., Kawasumi, M., Inagaki, S., Usuki, A., \& Sugiyama, S. (1988). US Patent No. 4,739,007. Japan: Toyota Motor Co.

10. Hartikainen, J., Hine, P., Szabó, J. S., Lindner, M., Harmia, T., Duckett, R. A., \& Friedrich, K. (2005). Polypropylene hybrid composites reinforced with long glass fibres and particulate filler. Composites Science and Technology, 65(2), 257-267. http://dx.doi.org/10.1016/j.compscitech.2004.07.010.

11. Rahman, N. A., Hassan, A., Yahya, R., Lafia-Araga, R. A., \& Hornsby, P. R. (2012). Micro-structural, thermal and mechanical properties of injection-molded glass-fiber/nanoclay/polypropylene composites. Journal of Reinforced Plastics and Composites, 31(4), 269-281. http://dx.doi.org/10.1177/0731684411435727.

12. Rahman, N. A., Hassan, A., Yahya, R., Lafia-Araga, R. A., \& Hornsby, P. R. (2012). Polypropylene/glass fiber/nanoclay hybrid composites: morphological, thermal, dynamic mechanical and impact behaviors. Journal of Reinforced Plastics and Composites, 31(18), 1247-1257. http://dx.doi. org/10.1177/0731684412456445.

13. Mohan, T. P., \& Kanny, K. (2011). Influence of nanoclay on rheological and mechanical properties of short glass fiberreinforced polypropylene composites. Journal of Reinforced
Plastics and Composites, 30(2), 152-160. http://dx.doi. org/10.1177/0731684410391509.

14. Cui, Y. H., Wang, X. X., Li, Z. Q., \& Tao, J. (2010). Fabrication and properties of nano $\mathrm{ZnO} /$ glass fiber reinforced polypropylene composites. Journal of Vinyl \& Additive Technology, 16(3), 189-194. http://dx.doi.org/10.1002/vnl.20231.

15. Essabir, H., Bensalah, M. O., Rodrigue, D., Bouhfid, R., \& Qaiss, A. (2016). Structural, mechanical and thermal properties of bio-based hybrid composites from waste coir residues: fibers and shell particles. Mechanics of Materials, 93, 134-144. http:// dx.doi.org/10.1016/j.mechmat.2015.10.018.

16. American Society for Testing and Materials-ASTM. (2003). ASTM D-638: standard test method for tensile properties of plastics. West Conshohocken: ASTM. http://dx.doi.org/10.1520/ D0638-03.

17. Hong, C. K., Kim, M. J., Oh, S. H., Lee, Y. S., \& Nah, C. (2008). Effects of polypropylene-g-(maleic anhydride/styrene) compatibilizer on mechanical and rheological properties of polypropylene/clay nanocomposites. Journal of Industrial and Engineering Chemistry, 14(2), 236-242. http://dx.doi. org/10.1016/j.jiec.2007.11.001.

18. Tarameshlou, M., Jafari, S. H., Khonakdar, H. A., Fakhravar, A., \& Farmahini-Farahani, M. (2010). PET-based nanocomposites made by reactive and remodified clays. Iranian Polymer Journal, 19(7), 521-529. Retrieved in 2015, October 11, from http://journal.ippi.ac.ir

19. Patel, H. A., Somani, R. S., Bajaj, H. C., \& Jasra, R. V. (2006). Nanoclays for polymer nanocomposites, paints, inks, greases and cosmetics formulations, drug delivery vehicle and waste water treatment. Bulletin of Materials Science, 29(2), 133-145. http://dx.doi.org/10.1007/BF02704606.

20. Kanny, K., Jawahar, P., \& Moodley, V. K. (2008). Mechanical and tribological behavior of clay-polypropylene nanocomposites. Journal of Materials Science, 43(22), 7230-7238. http://dx.doi. org/10.1007/s10853-008-2938-x.

21. Lertwimolnun, W., \& Vergnes, B. (2005). Influence of compatibilizer and processing conditions on the dispersion of nanoclay in a polypropylene matrix. Polymer, 46(10), 3462-3471. http://dx.doi.org/10.1016/j.polymer.2005.02.018.

22. Lee, S. Y., Kang, I. A., Doh, G. H., Kim, W. J., Kim, J. S., Yoon, H. G., \& Wu, Q. H. (2008). Thermal, mechanical and morphological properties of polypropylene/clay/wood flour nanocomposites. Express Polymer Letters, 2(2), 78-87. http:// dx.doi.org/10.3144/expresspolymlett.2008.11.

23. Zanetti, M., Camino, G., Reichert, P., \& Mülhaupt, R. (2001). Thermal behaviour of poly(propylene) layered silicate nanocomposites. Macromolecular Rapid Communications, 22(3), 176-180. http://dx.doi.org/10.1002/1521-3927(200102)22:3<176::AIDMARC176>3.0.CO;2-C.

24. Saha, A. K., Das, S., Bhatta, D., \& Mitra, B. C. (1999). Study of jute fiber reinforced polyester composites by dynamic mechanical analysis. Journal of Applied Polymer Science, 71(9), 1505-1513. http://dx.doi.org/10.1002/(SICI)10974628(19990228)71:9<1505::AID-APP15>3.0.CO;2-1.

25. American Society for Testing and Materials - ASTM. (2003). ASTM D-790-10: standard test method for flexural properties of unreinforced and reinforced plastics and electrical insulating materials. West Conshohocken: ASTM. http://dx.doi.org/10.1520/ D0790-10.

26. Lee, S. H., Kim, S. Y., \& Youn, J. R. (2009). Effects of maleination and heat treatment on morphology and dynamic mechanical thermal behavior of polypropylene/organoclay nanocomposites. Composites. Part A, Applied Science and Manufacturing, 40(6), 968-974. http://dx.doi.org/10.1016/j. compositesa.2009.03.013. 
27. Wang, Y., Chen, F. B., Li, Y. C., \& Wu, K. C. (2004). Melt processing of polypropylene/clay nanocomposites modified with maleated polypropylene compatibilizers. Composites. Part B, Engineering, 35(2), 111-124. http://dx.doi.org/10.1016/ S1359-8368(03)00049-0.

28. Modesti, M., Lorenzetti, A., Bon, D., \& Besco, S. (2006). Thermal behaviour of compatibilised polypropylene nanocomposite: effect of processing conditions. Polymer Degradation \& Stability, 91(4), 672-680. http://dx.doi.org/10.1016/j. polymdegradstab.2005.05.018.

29. Lai, S. M., Chen, W. C., \& Zhu, X. S. (2009). Melt mixed compatibilized polypropylene/clay nanocomposites. Part 1: the effect of compatibilizers on optical transmittance and mechanical properties. Composites. Part A, Applied Science and Manufacturing, 40(6-7), 754-765. http://dx.doi.org/10.1016/j. compositesa.2009.03.006.

30. Mandal, S., \& Alam, S. (2012). Dynamic mechanical analysis and morphological studies of glass/bamboo fiber reinforced unsaturated polyester resin-based hybrid composites. Journal of Applied Polymer Science, 125(S1), E382-E387. http://dx.doi. org/10.1002/app.36304.

31. Nayak, S. K., \& Mohanty, S. (2010). Sisal glass fiber reinforced PP hybrid composites: effect of MAPP on the dynamic mechanical and thermal properties. Journal of Reinforced Plastics and Composites, 29(10), 1551-1568. http://dx.doi. org/10.1177/0731684409337632.

32. Chen, M., Wan, C., Shou, W., Zhang, Y., Zhang, J., \& Zhang, J. (2008). Effects of interfacial adhesion on properties of polypropylene/Wollastonite composites. Journal of Applied Polymer Science, 107(3), 1718-1723. http://dx.doi.org/10.1002/ app. 23535 .

Received: Oct. 11, 2015

Revised: May 23, 2016

Accepted: May 30, 2016 